\title{
AGENTES DE IGUALDAD EN LA ADMINISTRACIÓN PÚBLICA ESPAÑOLA Y FRANCESA: BASES DE CONTRATACIÓN
}

\author{
Eva Tobías Olarte \\ Universidad de La Rioja \\ Soline Blanchard \\ Universidad de Toulouse II - Le Mirail
}

RESUMEN: Este artículo presenta la situación de la figura profesional de Agente de Igualdad, en España y en Francia, partiendo de un análisis de las condiciones de acceso y desempeño de la profesión en el sector público. Las autoras coinciden en señalar la importancia de la labor que desarrollan las y los especialistas de igualdad, y por tanto, señalan la necesidad de exigir una formación, experiencia y competencias mínimas para ejercer esta profesión con garantías de éxito.

Palabras clave: Agente de Igualdad, selección y contratación, administración pública.

\section{GENDER EXPERT IN SPAIN AND FRANCE: ANALYSIS OF ACCESS CONDITIONS AND EXERCISE OF THE PROFESSION IN THE PUBLIC SECTOR}

ABSTRACT: This article describes the situation of the professional figure of Gender Expert in Spain and France, based on the analysis of access conditions and exercise of the profession in the public sector. The authors outline how important are the Gender Expert's duties in promoting equality, and explain the underlying minimum training, experience and skills requirements needed to improve the effectiveness and the quality of their assignements.

Keywords: Gender Expert, recruiting, public administration. 
"No podemos entender la salud sin profesionales de la medicina y la enfermería, sin profesionales de la salud. No podemos entender la educación sin maestras y maestros, sin profesoras y profesores. Tampoco podemos entender las obras e infraestructuras sin arquitectas y arquitectos, aparejadoras y aparejadores, albañilas y albañiles. Sin embargo, esta correlación no se da cuando hablamos de lgualdad de Género" (Manifiesto del I Congreso de Agentes de Igualdad de Pontevedra, 2004).

\section{Introducción: la figura profesional de Agente de Igualdad en España}

La igualdad entre mujeres y hombres es un principio jurídico universal reconocido en diversos textos internacionales ${ }^{1}$. La igualdad es, asimismo, un pilar en el que se fundamenta la Unión Europea. De hecho, en marzo de 2010, la Comisión Europea adoptó la Carta de la Mujer², en la que renueva su compromiso por la igualdad entre los sexos y la consolidación de la perspectiva de género en todas sus políticas ${ }^{3}$.

En España, la Constitución de 1978 incorpora el principio de igualdad como un derecho fundamental, en su artículo $14^{4}$, y como un mandato a los poderes públicos en el artículo $9.2^{5}$. Pero es a raíz de la aprobación de la Ley Orgánica 3/2007, de 22 de marzo, para la igualdad efectiva de mujeres y hombres ${ }^{6}$, cuando se impulsan realmente las políticas activas para hacer efectivo el principio de igualdad. Esto implica necesariamente una proyección general del principio de igualdad en los diversos ámbitos del ordenamiento jurídico como el educativo, laboral, económico o social. En este sentido, la Ley pretende en último término "alcanzar una sociedad más democrática, más justa y más solidaria"7.

No obstante, de esta preocupación por lograr la igualdad efectiva en nuestra sociedad, no puede quedar fuera la concreción y el impulso de las y

1. Agradecemos de manera especial la colaboración de todas las personas que, de algún modo, han contribuido en la elaboración del presente artículo, y en particular, la de Béatrice Pépin por la traducción del caso francés.

2. $\operatorname{COM}(2010) 78$.

3. COM (2010) 491 final, en relación a la Estrategia para la igualdad entre mujeres y hombres 2010-2015.

4. "Los españoles son iguales ante la Ley, sin que pueda prevalecer discriminación alguna por razón de nacimiento, raza, sexo, religión, opinión o cualquier otra condición o circunstancia personal o social".

5. "Corresponde a los poderes públicos promover las condiciones para que la libertad y la igualdad del individuo y de los grupos en que se integra sean reales y efectivas; remover los obstáculos que impidan o dificulten su plenitud y facilitar la participación de todos los ciudadanos en la vida política, económica, cultural y social".

6. BOE número 71 de 23/03/2007.

7. Artículo 1 de la Ley Orgánica 3/2007, de 22 de marzo, para la igualdad efectiva de mujeres y hombres. 
$\operatorname{los}^{8}$ especialistas en materia de igualdad. En España, en la actualidad, existen dos figuras diferenciadas en este ámbito de trabajo: Agente de Igualdad y Promotor/a de Igualdad. Ambos perfiles están reconocidos en la nueva Clasificación Nacional de Ocupaciones ${ }^{9}$ (C.N.O) de la siguiente manera:

2825: Agentes de igualdad de oportunidades entre mujeres y hombres.

3714: Promotore ${ }^{10}$ de igualdad de oportunidades entre mujeres $y$ hombres.

La diferencia entre ambas figuras en teoría es clara, aunque en la práctica puede existir cierto solapamiento entre las dos. Por un lado, la profesión de Agente de Igualdad requiere una formación universitaria (diplomatura o licenciatura) y sus funciones están relacionadas con el diseño, ejecución, seguimiento y evaluación de programas y acciones que impulsen la igualdad de mujeres y hombres, y por otro, la figura de Promotor/a de Igualdad está más centrada en tareas de atención directa a las personas que utilizan servicios dirigidos a las mujeres, y en este caso no se requiere formación universitaria ${ }^{11}$.

A pesar de la existencia de estos dos perfiles, es la figura profesional de Agente de Igualdad la que se ha ido consolidando en estos últimos años, principalmente en el ámbito público. Muchas administraciones han sido conscientes del valor añadido y el potencial transformador que suponía la incorporación de estas y estos profesionales al sector público. Tampoco hay que olvidar que muchas entidades han visto la posibilidad de trabajar la igualdad de mujeres y hombres, al poder contar con subvenciones (en algunas comunidades autónomas) que sufragaban en parte los costes de incorporación en plantilla de Agentes de Igualdad. Navarra' ${ }^{12}$ y Castilla y León ${ }^{13}$ son dos ejemplos de ello.

Sin embargo, las diferentes condiciones con las que se han encontrado las y los Agentes de Igualdad a la hora de acceder a un empleo en la administración pública española, nos lleva a reflexionar sobre las barreras con las que se encuentran este tipo de profesionales a la hora de acceder y desempeñar su profesión. Esta cuestión no nos puede dejar inmunes si queremos contar con verdaderas expertas y expertos en igualdad, que cuenten con nuestro re-

8. En este artículo, al hablar de la figura de Agente de Igualdad, utilizaremos en primer lugar el artículo determinado femenino al ser una profesión altamente feminizada.

9. Real Decreto 1591/2010, de 26 de noviembre, por el que se aprueba la Clasificación Nacional de Ocupaciones 2011.

10. Se utiliza un lenguaje sexista en la denominación de la ocupación ("Promotores").

11. Fernández Garrido, J., Aramburu-Zabala Higuera, L., "Formación profesional para especialistas en el área de igualdad de oportunidades para las mujeres". Revista Europea de Formación Profesional 23 (2001), pp. 73-79.

12. ORDEN FORAL 410/2010, de 31 de diciembre, de la Consejera de Asuntos Sociales, Familia, Juventud y Deporte, por la que se aprueba la convocatoria para la concesión de subvenciones, en el año 2011, por el Instituto Navarro para la Igualdad, a Entidades Locales de Navarra para la incorporación y consolidación de Agentes de Igualdad de Oportunidades.

13. ORDEN FAM/112/2009, de 20 de enero, por la que se aprueban las bases reguladoras que han de regir las convocatorias de subvenciones a efectuar por la Consejería de Familia e Igualdad de Oportunidades. 
conocimiento a su labor. Por tanto, tampoco debemos olvidar la importancia de trabajar para que, en un futuro no muy lejano, se sienten las bases de una certificación profesional ${ }^{14}$ que ponga sobre la mesa la formación, experiencia y competencias necesarias para ejercer esta profesión con garantías.

\section{Oferta formativa específica}

Casi al mismo tiempo que muchos ayuntamientos iban incorporando Agentes de Igualdad en sus plantillas, las universidades españolas incluían en su oferta formativa, Másters o postgrados en materia de igualdad y género. En este caso, podemos diferenciar dos tipos de formación: una dirigida específicamente a la figura profesional de Agente de Igualdad, y otra destinada a cuestiones concretas como la violencia de género o la investigación feminista. Algunas universidades se decantan por una de estas formaciones, y otras incluyen en su catálogo formativo ambos tipos de estudios.

Hay que señalar que desde diversos organismos y asociaciones, se reclama una formación homogénea que abra las puertas al desempeño de la profesión de Agente de Igualdad, y que sirva de sustento para la posterior certificación profesional de dicha figura. Estaríamos hablando de una formación mínima de 60 ECTS $^{15}$, con título de Máster e impartida por una universidad pública.

En el siguiente cuadro se recoge la formación específica de Agentes de Igualdad que en la actualidad, es ofertada por universidades públicas españolas. La lista no es exhaustiva, pero pretende señalar el auge de estos estudios a nivel nacional.

Además, en este sentido, debemos destacar dos iniciativas muy recientes y ambiciosas, que suponen una clara apuesta por este tipo de estudios: la puesta en marcha de un Grado en Igualdad de Género por la Universidad Rey Juan Carlos $^{16}$, y la impartición del Máster universitario Erasmus Mundus en Estudios de las Mujeres y de Género, único programa Erasmus Mundus en esta materia que está avalado por la Comisión europea (impartido por 8 universidades europeas) ${ }^{17}$.

14. Señala Carmen Ruiz Bueno en su artículo "La certificación profesional: algunas reflexiones y cuestiones a debate" que "La certificación representa, además, un valor añadido para la persona, pues supone un reconocimiento público, otorgándole un status personal dentro y fuera de las instituciones donde desarrolla su trabajo".

15. European Credit Transfer System.

16. http://www.urjc.es/estudios/grado/igualdad_genero/igualdad_genero.html.

17. http://www.ugr.es/ gemma/. 


\begin{tabular}{|c|c|c|c|}
\hline Región & Universidad & Denominación Formación & Características \\
\hline Andalucía & $\begin{array}{l}\text { Universidad de } \\
\text { Sevilla. }\end{array}$ & $\begin{array}{l}\text { Experto/a universitario en Agente de } \\
\text { Igualdad }{ }^{18} .\end{array}$ & $\begin{array}{l}\text { - Título propio. } \\
\text { - Semipresencial. } \\
\text { - } 30 \text { ECTS. }\end{array}$ \\
\hline Aragón & $\begin{array}{l}\text { Universidad de } \\
\text { Zaragoza. }\end{array}$ & $\begin{array}{l}\text { Postgrado en Agentes de Igualdad de } \\
\text { Oportunidades para las mujeres }{ }^{19} \text {. }\end{array}$ & $\begin{array}{l}\text { - Título propio. } \\
\text { - Semipresencial. } \\
\text { - } 20 \text { ECTS. }\end{array}$ \\
\hline $\begin{array}{l}\text { Castilla La } \\
\text { Mancha }\end{array}$ & $\begin{array}{l}\text { Universidad } \\
\text { Castilla La } \\
\text { Mancha. }\end{array}$ & $\begin{array}{l}\text { Máster en Igualdad. Formación de } \\
\text { Agentes para la Igualdad }{ }^{20} \text {. }\end{array}$ & $\begin{array}{l}\text { - Título propio. } \\
\text { - Presencial. } \\
\text { - } 60 \text { ECTS. }\end{array}$ \\
\hline Cataluña & $\begin{array}{l}\text { Universidad de } \\
\text { Lleida. }\end{array}$ & $\begin{array}{c}\text { Máster en Agentes de Igualdad de } \\
\text { Oportunidades para las mujeres: ámbito } \\
\text { rural }^{21} \text {. }\end{array}$ & $\begin{array}{l}\text { - Título oficial. } \\
\text { - } 60 \text { ECTS. }\end{array}$ \\
\hline \multirow[b]{2}{*}{$\begin{array}{l}\text { Comunidad } \\
\text { Valenciana }\end{array}$} & $\begin{array}{l}\text { Universidad } \\
\text { Jaime I de } \\
\text { Castellón. }\end{array}$ & Especialista en Agente de Igualdad ${ }^{22}$. & $\begin{array}{l}\text { - Título propio. } \\
\text { - Online. } \\
\text { - } 33 \text { ECTS. }\end{array}$ \\
\hline & $\begin{array}{l}\text { Universidad de } \\
\text { Valencia. }\end{array}$ & $\begin{array}{l}\text { Diploma de Especialización Profesional } \\
\text { Universitario en Normativa Aplicable } \\
\text { en Materia de Igualdad entre Mujeres y } \\
\text { Hombres en el trabajo: Agentes por la } \\
\text { Igualdad entre Mujeres y Hombres }{ }^{23} \text {. }\end{array}$ & $\begin{array}{l}\text { - Título propio. } \\
\text { - A distancia. }\end{array}$ \\
\hline Madrid & UNED. & $\begin{array}{l}\text { Experto universitario en Agentes de } \\
\text { Igualdad de Oportunidades para las } \\
\text { mujeres: acciones positivas en el marco } \\
\text { de la cooperación }{ }^{24} \text {. }\end{array}$ & $\begin{array}{l}\text { - Título propio. } \\
\text { - A distancia. } \\
\text { - } 30 \text { ECTS. }\end{array}$ \\
\hline País Vasco & $\begin{array}{l}\text { Universidad } \\
\text { del País Vasco. }\end{array}$ & $\begin{array}{l}\text { Igualdad de mujeres y hombres: agentes } \\
\text { de igualdad }{ }^{25} .\end{array}$ & $\begin{array}{l}\text { - Título propio. } \\
\text { - Semipresencial. } \\
\text { - } 60 \text { ECTS. }\end{array}$ \\
\hline
\end{tabular}

18. http://www.fundacionmujeres.es/img/Evento/1033/documento.pdf.

19. http://www.unizar.es/servicios/epropios/oferta.html.

20. http://www.uclm.es/Actividades/repositorio/pdf/doc_2394_2917.pdf.

21. http://www.agentsigualtatdones.udl.cat/export/sites/lgualtat/Documents/MAIO_1011_ esp.pdf.

22. http://isonomia.uji.es/archivos/dipticos/2010/agenteigualdad.pdf.

23. http://www.adeit.uv.es/postgrado/.

24. http://www.fundacion.uned.es/cursos/derecho/especialista/igualdad-mujeres-hombres/.

25. http://www.sc.ehu.es/sswigual/. 


\section{Las condiciones de acceso y desempeño de la profesión}

La profesión de Agente de Igualdad ofrece un perfil de demanda creciente por parte de las administraciones públicas y, en menor medida, por las organizaciones privadas. Ya en la Recomendación de la Comisión Europea de 24 de noviembre de 1987 sobre la formación profesional de las mujeres ${ }^{26}$, en su artículo 2.b se recomendaba a los Estados miembros "la formación y contratación de personal cualificado para responder a los problemas específicos de las mujeres (por ejemplo, consejeros en materia de igualdad)...". Por otro lado, a nivel nacional, el IV Plan de Igualdad de Oportunidades entre hombres y mujeres (2003$2006)^{27}$ del Ministerio de Trabajo y Asuntos Sociales, recomendaba impulsar el reconocimiento oficial del título profesional de Agentes de Igualdad, dentro del área de introducción de la perspectiva de género en las políticas públicas.

No obstante, y a pesar de la creciente demanda de este tipo de profesionales, nos encontramos con una clara desorientación por parte de las entidades contratantes a la hora de seleccionar personal experto en igualdad de género. Esto se traduce en una serie de obstáculos que se presentan en el momento de acceso a la profesión de Agente de Igualdad y que se perpetúan en el tiempo. Podemos definir obstáculo como "un inconveniente o un estorbo para conseguir unos objetivos $\operatorname{concretos}^{\prime 28}$. Hemos de señalar que si existe una clara apuesta por parte de las entidades públicas contratantes, por conseguir personal cualificado y motivado para trabajar en la transformación de las relaciones de desigualdad entre hombres y mujeres, deberemos tratar de eliminar dichos "inconvenientes o estorbos".

La diferencia en los sistemas de acceso (oposición y/o concurso), en la categoría laboral, régimen de contratación y retribución, y la divergencia de requisitos de titulación y criterios de valoración que establecen las administraciones públicas para incorporar a este tipo de profesionales, son algunos de los obstáculos con los que nos encontramos.

Es de justicia por tanto, trabajar en la consecución de unas condiciones laborales y profesionales dignas, que faciliten a esta figura profesional posicionarse como pieza clave en la introducción de la perspectiva de género en organizaciones e instituciones, tanto públicas como privadas.

\subsection{Bases de contratación en la administración pública española en 2010}

En este apartado queremos reflejar las diferentes bases de contratación que rigen la provisión de plazas de Agente de Igualdad en la administración pública española, partiendo de una selección de convocatorias públicas del año 2010.

26. http://eur-lex.europa.eu/LexUriServ/LexUriServ.do?uri=CELEX:31987H0567:ES:HTML.

27. http://www.msc.es/organizacion/sns/planCalidadSNS/pdf/equidad/IV_Plan_lgualdad_ Hombre_Mujeres_2003-2006.pdf.

28. Fuente: Wikipedia. 
Convocatorias públicas (2010)

\begin{tabular}{|c|c|c|c|}
\hline Administración pública & Región & Fuente & Plazas \\
\hline $\begin{array}{c}\text { Diputación Provincial de } \\
\text { Granada }\end{array}$ & Andalucía & BOJA núm. 134 & 2 \\
\hline $\begin{array}{c}\text { Ayuntamiento de San Martín } \\
\text { del Rey Aurelio }\end{array}$ & Asturias & www.smra.eu & 1 \\
\hline Consejo Insular de Mallorca & Baleares & BOIB núm. 78 & 1 \\
\hline Ayuntamiento de Villablino & Castilla y León & www.aytovillablino.com & 1 \\
\hline Ayuntamiento de Benavente & Castilla y León & www.benavente.es & 1 \\
\hline $\begin{array}{c}\text { Ayuntamiento de Tudela de } \\
\text { Duero }\end{array}$ & Castilla y León & www.aytotudela.es & 1 \\
\hline $\begin{array}{c}\text { Ayuntamiento de Aguilar de } \\
\text { Campoo }\end{array}$ & Castilla y León & www.aguilardecampoo.com & 1 \\
\hline Ayuntamiento de Gavà & Cataluña & BOPB de 25 de octubre & 1 \\
\hline Ayuntamiento de Sabadell & Cataluña & DOGC núm. 5613 & 1 \\
\hline $\begin{array}{l}\text { Mancomunidad Sierra } \\
\text { Suroeste } \\
\end{array}$ & Extremadura & $\begin{array}{c}\text { http://mansierrasuroeste.dip- } \\
\text { badajoz.es }\end{array}$ & 1 \\
\hline $\begin{array}{c}\text { Diputación provincial de } \\
\text { Cáceres }\end{array}$ & Extremadura & B.O. de Cáceres núm. 146 & 1 \\
\hline $\begin{array}{c}\text { Ayuntamiento de Villanueva } \\
\text { del Pardillo }\end{array}$ & Madrid & BOCM núm. 108 & 1 \\
\hline Ayuntamiento de Barakaldo & País Vasco & BOB núm. 97 & 1 \\
\hline
\end{tabular}

Como podemos ver en el cuadro anterior, en el año 2010 la administración local ha sido el motor de la contratación y consolidación de la figura profesional de Agente de Igualdad ${ }^{29}$.

29. En este sentido, debemos señalar la particularidad de Navarra. El Instituto Navarro para la lgualdad (INAI) viene apostando en los últimos años por la incorporación de Agentes de Igualdad en los Ayuntamientos navarros de más de 7.000 habitantes, y en las mancomunidades establecidas con más de 10.000 habitantes. Para ello, y en colaboración con el Servicio Navarro de Empleo (SNE), elabora una lista de aspirantes que es utilizada para aquellas ofertas presentadas por las entidades locales al SNE. Dicha lista tiene una vigencia estimada de 2 años. Al mismo tiempo, el INAI apoya y financia a las entidades locales para estas nuevas contrataciones. El presupuesto destinado a tal efecto en 2010, fue de 240.000 euros. 


\section{Condiciones}

Las condiciones recogidas en las diferentes convocatorias públicas, en relación al sistema de acceso, categoría laboral y régimen de contratación, retribución y jornada se reflejan en el siguiente cuadro.

\begin{tabular}{|c|c|c|c|c|}
\hline Organismo & Sistema & Categoría / Régimen & Salario & Jornada \\
\hline $\begin{array}{l}\text { Diputación Provincial de } \\
\text { Granada }\end{array}$ & $\begin{array}{l}\text { Concurso- } \\
\text { oposición }\end{array}$ & $\begin{array}{l}\text { Funcionario/a de carrera. } \\
\text { Grupo A, Subgrupo A2. }\end{array}$ & $\begin{array}{c}\text { Grupo A, } \\
\text { Subgrupo A2 }\end{array}$ & No consta \\
\hline $\begin{array}{c}\text { Ayuntamiento de San Martín } \\
\text { del Rey Aurelio }\end{array}$ & $\begin{array}{l}\text { Concurso- } \\
\text { oposición }\end{array}$ & $\begin{array}{c}\text { Contratación laboral por obra } \\
\text { y servicio. }\end{array}$ & No consta & No consta \\
\hline Consejo Insular de Mallorca & Concurso & $\begin{array}{c}\text { Bolsa de la subescala, clase o } \\
\text { categoría de Agente Local de } \\
\text { ggualdad. Grupo A2. } \\
\text { Carácter de interinidad. }\end{array}$ & No consta & No consta \\
\hline Ayuntamiento de Villablino & Concurso & $\begin{array}{l}\text { Contratación laboral por } \\
\text { obra y servicio de duración } \\
\text { determinada. } \\
\text { Categoría: titulación media. }\end{array}$ & $\begin{array}{c}965,17 € / \\
\text { mensuales }^{30}\end{array}$ & No consta \\
\hline Ayuntamiento de Benavente & $\begin{array}{l}\text { Concurso- } \\
\text { oposición }\end{array}$ & $\begin{array}{l}\text { Contratación laboral de } \\
\text { carácter temporal. }\end{array}$ & No consta & No consta \\
\hline $\begin{array}{c}\text { Ayuntamiento de Tudela de } \\
\text { Duero }\end{array}$ & Concurso & $\begin{array}{c}\text { Contratación laboral de } \\
\text { carácter temporal. }\end{array}$ & $\begin{array}{l}695 € \text { brutos/ } \\
\text { mensuales }^{31}\end{array}$ & Parcial \\
\hline $\begin{array}{l}\text { Ayuntamiento de Aguilar de } \\
\text { Campoo }\end{array}$ & Concurso & $\begin{array}{l}\text { Contratación laboral de } \\
\text { carácter temporal. }\end{array}$ & No consta & Parcial \\
\hline Ayuntamiento de Gavà & $\begin{array}{l}\text { Concurso- } \\
\text { oposición }\end{array}$ & $\begin{array}{c}\text { Contratación laboral de } \\
\text { carácter temporal. }\end{array}$ & No consta & $\begin{array}{l}37,5 \text { horas } \\
\text { semanales }\end{array}$ \\
\hline Ayuntamiento de Sabadell & Concurso & $\begin{array}{c}\text { Funcionario/a. Interinidad } \\
\text { temporal. }\end{array}$ & No consta & No consta \\
\hline $\begin{array}{l}\text { Mancomunidad Sierra } \\
\text { Suroeste }\end{array}$ & $\begin{array}{l}\text { Concurso- } \\
\text { oposición }\end{array}$ & No consta. & No consta & $\begin{array}{c}40 \text { horas } \\
\text { semanales }\end{array}$ \\
\hline $\begin{array}{c}\text { Diputación provincial de } \\
\text { Cáceres }\end{array}$ & $\begin{array}{l}\text { Concurso- } \\
\text { oposición }\end{array}$ & $\begin{array}{c}\text { Contratación laboral de } \\
\text { carácter fijo. } \\
\text { Subgrupo A1. }\end{array}$ & Subgrupo A1 & No consta \\
\hline $\begin{array}{c}\text { Ayuntamiento de Villanueva } \\
\text { del Pardillo }\end{array}$ & Concurso & $\begin{array}{l}\text { Contratación laboral de } \\
\text { carácter temporal. } \\
\text { Grupo A2. }\end{array}$ & Grupo A2 & No consta \\
\hline Ayuntamiento de Barakaldo & $\begin{array}{l}\text { Concurso- } \\
\text { oposición }\end{array}$ & $\begin{array}{c}\text { Funcionario/a de carrera. } \\
\text { Subgrupo A2. }\end{array}$ & Subgrupo A2 & No consta \\
\hline
\end{tabular}

30. Retribución mensual bruta.

31. Se incluye la parte proporcional de la paga extra. 
La mayoría de las plazas convocadas son temporales y no se especifica ni la retribución ni si la jornada es a tiempo completo o parcial.

En relación al sistema de acceso, la mitad de las convocatorias señaladas plantean un sistema mixto de concurso-oposición. Si analizamos la fase de oposición, podemos ver la heterogeneidad del temario exigido. Por otro lado, es interesante comprobar si en éste se ha incluido un tema específico sobre la figura profesional de Agente de Igualdad.

Sistema oposición: temario

\begin{tabular}{|c|c|c|}
\hline Organismo & Temario & $\begin{array}{c}\text { Tema específico sobre } \\
\text { la figura de } \mathrm{AIO}^{32}\end{array}$ \\
\hline $\begin{array}{c}\text { Diputación Provincial } \\
\text { de Granada }\end{array}$ & $\begin{array}{c}60 \text { temas. } \\
\text { Bloque I: } 12 \text { temas (legislación). } \\
\text { Bloque II: } 48 \text { temas (igualdad). }\end{array}$ & $\begin{array}{l}\text { Si (tema } 15, \\
\text { bloque II) }\end{array}$ \\
\hline $\begin{array}{l}\text { Ayuntamiento de San } \\
\text { Martín del Rey Aurelio }\end{array}$ & 8 temas. & No \\
\hline $\begin{array}{c}\text { Ayuntamiento de } \\
\text { Benavente }\end{array}$ & 12 temas. & No \\
\hline $\begin{array}{l}\text { Mancomunidad Sierra } \\
\text { Suroeste }\end{array}$ & 9 temas. & No \\
\hline $\begin{array}{c}\text { Diputación Provincial } \\
\text { de Cáceres }\end{array}$ & $\begin{array}{l}90 \text { temas. } \\
\text { Bloque I: } 20 \text { temas (legislación). } \\
\text { Bloque II: } 70 \text { temas (igualdad). }\end{array}$ & $\begin{array}{l}\text { Sí (tema } 48, \\
\text { bloque II) }\end{array}$ \\
\hline $\begin{array}{c}\text { Ayuntamiento de } \\
\text { Barakaldo }\end{array}$ & $\begin{array}{c}60 \text { temas. } \\
\text { Bloque I: } 12 \text { temas (legislación). } \\
\text { Bloque II: } 48 \text { temas (igualdad). }\end{array}$ & No \\
\hline
\end{tabular}

El Ayuntamiento de Gavà no plantea un temario concreto, sino que basa la fase de oposición en la realización de un caso práctico sobre las funciones de técnico/a de igualdad establecidas en la base de la convocatoria.

\section{Requisitos}

A la hora de definir un puesto de trabajo, es primordial tener claro qué requisitos son los idóneos que debemos exigir para conseguir un adecuado ejercicio del mismo. Este punto implica tener la capacidad de separar las condiciones absolutamente necesarias (requisitos) para ocupar el puesto con

32. Agente de Igualdad de Oportunidades. 
unas mínimas garantías, de los criterios de valoración (méritos), de los que hablaremos más tarde.

Detengámonos pues en los requisitos de titulación y formación de las plazas de Agente de Igualdad convocadas en 2010.

\begin{tabular}{|c|c|c|}
\hline Organismo & Titulación & Formación como AIO \\
\hline $\begin{array}{l}\text { Diputación Provincial } \\
\text { de Granada }\end{array}$ & $\begin{array}{l}\text { Diplomatura universitaria, Ingeniería Técni- } \\
\text { ca, Arquitectura Técnica, Formación Profe- } \\
\text { sional de tercer grado o equivalente. }\end{array}$ & No consta \\
\hline $\begin{array}{l}\text { Ayuntamiento de San } \\
\text { Martín del Rey Aurelio }\end{array}$ & \multicolumn{2}{|c|}{$\begin{array}{l}\text { Titulación universitaria de Derecho, Ciencias del Trabajo, Relaciones La- } \\
\text { borales o Graduado Social, Trabajo Social o Educador Social o Ciencias } \\
\text { Sociales o de la Información, Psicología o Pedagogía. } \\
\text { Las personas con titulación media o superior diferente a la relacionada } \\
\text { pueden optar, pero en este caso deberán poseer una formación mínima de } \\
200 \text { horas relacionada con la ocupación de Agente de Igualdad. }\end{array}$} \\
\hline $\begin{array}{l}\text { Consejo Insular de } \\
\text { Mallorca }\end{array}$ & $\begin{array}{l}\text { Diplomatura en Trabajo Social, Relaciones } \\
\text { Laborales, Magisterio, Empresariales y Edu- } \\
\text { cación Social o tres años completos de las } \\
\text { licenciaturas de Derecho, Económicas, Pe- } \\
\text { dagogía, Psicología, Sociología, Antropolo- } \\
\text { gía, Historia, Geografía, Filología, Filosofía. }\end{array}$ & No consta \\
\hline $\begin{array}{l}\text { Ayuntamiento de } \\
\text { Villablino }\end{array}$ & $\begin{array}{l}\text { Título de Grado Medio o Superior en el ám- } \\
\text { bito de las Ciencias Sociales o Jurídicas. }\end{array}$ & $\begin{array}{l}\text { Formación acreditada } \\
\text { como Agente de Igualdad } \\
\text { de al menos } 135 \text { horas }^{33}\end{array}$ \\
\hline $\begin{array}{l}\text { Ayuntamiento de } \\
\text { Benavente }\end{array}$ & $\begin{array}{l}\text { Título de Grado Medio o Superior en el ám- } \\
\text { bito de las Ciencias Sociales o Jurídicas. }\end{array}$ & $\begin{array}{l}\text { Formación acreditada } \\
\text { como Agente de Igualdad } \\
\text { de al menos } 135 \text { horas }^{33}\end{array}$ \\
\hline $\begin{array}{l}\text { Ayuntamiento de } \\
\text { Tudela de Duero. }\end{array}$ & $\begin{array}{l}\text { Título de Grado Medio o Superior en el ám- } \\
\text { bito de las Ciencias Sociales o Jurídicas. }\end{array}$ & $\begin{array}{l}\text { Formación acreditada } \\
\text { como Agente de Igualdad } \\
\text { de al menos } 135 \text { horas }^{33}\end{array}$ \\
\hline $\begin{array}{l}\text { Ayuntamiento de } \\
\text { Aguilar de Campoo }\end{array}$ & $\begin{array}{l}\text { Título de Grado Medio o Superior en el ám- } \\
\text { bito de las Ciencias Sociales o Jurídicas. }\end{array}$ & $\begin{array}{l}\text { Formación acreditada } \\
\text { como Agente de Igualdad } \\
\text { de al menos } 135 \text { horas }^{33}\end{array}$ \\
\hline $\begin{array}{l}\text { Ayuntamiento de } \\
\text { Gavà }\end{array}$ & $\begin{array}{l}\text { Diplomatura en Trabajo Social o haber su- } \\
\text { perado } 3 \text { cursos completos o tener como } \\
\text { mínimo } 180 \text { créditos aprobados de las li- } \\
\text { cenciaturas de Psicología, Sociología o } \\
\text { Ciencias Políticas. }\end{array}$ & No consta \\
\hline
\end{tabular}

33. O contar con una experiencia laboral constatable de al menos dos años en el desarrollo de actuaciones relacionadas con la igualdad de oportunidades entre mujeres y hombres. 


\begin{tabular}{|c|c|c|}
\hline Organismo & Titulación & Formación como AlO \\
\hline $\begin{array}{l}\text { Ayuntamiento de } \\
\text { Sabadell }\end{array}$ & $\begin{array}{l}\text { Diplomatura universitaria o haber superado } \\
\text { los } 3 \text { primeros cursos completos de una li- } \\
\text { cenciatura o haber superado un primer ciclo } \\
\text { y haber realizado en conjunto } 180 \text { créditos } \\
\text { de una licenciatura en el ámbito de las cien- } \\
\text { cias sociales y humanidades. }\end{array}$ & No consta \\
\hline $\begin{array}{l}\text { Mancomunidad Sierra } \\
\text { Suroeste }\end{array}$ & $\begin{array}{l}\text { Titulación universitaria de grado medio o } \\
\text { superior. }\end{array}$ & No consta \\
\hline $\begin{array}{c}\text { Diputación provincial } \\
\text { de Cáceres }\end{array}$ & Licenciatura en Derecho o Sociología. & $\begin{array}{l}\text { Formación acreditada por } \\
\text { Organismos públicos en } \\
\text { igualdad de oportunidades }\end{array}$ \\
\hline $\begin{array}{c}\text { Ayuntamiento de } \\
\text { Villanueva del Pardillo }\end{array}$ & $\begin{array}{l}\text { Diplomatura universitaria en Trabajo Social } \\
\text { o Educación Social o titulación superior en } \\
\text { Pedagogía, Sociología o Psicología. }\end{array}$ & No consta \\
\hline $\begin{array}{l}\text { Ayuntamiento de } \\
\text { Barakaldo }\end{array}$ & $\begin{array}{l}\text { Diplomatura en Trabajo Social o Educación } \\
\text { Social. }\end{array}$ & No consta \\
\hline
\end{tabular}

Los requisitos en relación a la titulación se centran principalmente en tener un grado medio o superior universitario, pero la mayoría de las bases concretan las ramas de especialización enfocándose en las ciencias sociales o jurídicas. Es curioso pensar que otro tipo de formaciones en ciencias o tecnología por ejemplo, no puedan aportar un conocimiento y un "saber hacer" en el campo de la igualdad, cuando desde hace ya tiempo se viene trabajando precisamente en integrar la perspectiva de género en los ámbitos científico, tecnológico y de innovación. Muestra de ello es la Unidad de Mujer y Ciencia del Ministerio de Ciencia e Innovación ${ }^{34}$.

Por otro lado, en relación a la formación específica de Agente de Igualdad vemos que algunas administraciones públicas o no la exigen (¿nos podemos imaginar qué pasaría si no exigiéramos un título de medicina a quién está ejerciendo en este campo?), o el número de horas requeridas es muy bajo (en este caso las administraciones locales de Castilla y León plasman literalmente las condiciones de la Orden que establece las bases de las subvenciones de la administración regional correspondiente).

Por último, es importante señalar que algunos Ayuntamientos añaden otros requisitos ineludibles para acceder al proceso de selección. El Ayuntamiento de San Martín del Rey Aurelio, por ejemplo, exige la residencia en uno de los setenta y ocho concejos asturianos o ser una persona desempleada ${ }^{35}$, entre otras

34. www.micinn.es.

35. Inscrita en una oficina de empleo del Principado de Asturias. 
cuestiones. Por otra parte, el Ayuntamiento de Villablino, la Mancomunidad Sierra Suroeste ${ }^{36}$, el Ayuntamiento de Aguilar de Campoo y el Consejo Insular de Mallorca requieren el permiso de conducción clase B1.

\section{Criterios de valoración}

La valoración de los méritos de las personas candidatas, basada en la puntuación de la experiencia y la formación, es uno de los métodos más utilizados por la administración pública española. Se trata de establecer una conexión entre la acreditación de una determinada formación o experiencia con un desempeño laboral exitoso, pero la utilización de los baremos no es sencilla, pues puede ser objeto de múltiples interpretaciones.

Como señala el artículo de Pamela Alonso, Gabriel Táuriz y Beata Choragwicka de la Universidad de Santiago de Compostela, "la valoración de méritos no siempre ofrece las necesarias garantías e igualdad, dado que existe una amplia discrecionalidad de cada administración para determinar los méritos del baremo correspondiente" ${ }^{\prime \prime 37}$. Además, en dicho artículo se recomienda por un lado, no usar una valoración de méritos sin haber realizado un análisis previo del puesto de trabajo, que permita relacionar los criterios a evaluar con el contenido de las tareas y funciones del puesto, y por otro, refleja la necesidad de no utilizar este instrumento en solitario por su escasa utilidad en predecir un desempeño exitoso.

\section{Servicios prestados en plaza o puesto de igual categoría y funciones que la plaza convocada (o puestos con contenido técnico análogo).}

Diputación Provincial de Granada (sector público).

Consejo Insular de Mallorca (sector público y privado).

Ayuntamiento de Villablino (sector público y privado).

Ayuntamiento de Benavente (sector público y privado).

Ayuntamiento de Tudela de Duero (no especifica).

Ayuntamiento de Aguilar de Campoo (sector público y privado).

Ayuntamiento de Gavà (sector público).

Ayuntamiento de Sabadell (sector público y privado).

Mancomunidad Sierra Suroeste (sector público).

Diputación Provincial de Cáceres (sector público y privado).

Ayuntamiento de Villanueva del Pardillo (sector público).

Ayuntamiento de Barakaldo (sector público).

36. También la disponibilidad de vehículo.

37. Alonso, P., Táuriz G., Choragwicka B., "Valoraciones de Méritos (Training and Experience) en la Administración Pública y la Empresa: Fiabilidad, Validez y Discriminación de Género". Revista de psicología del trabajo y de las organizaciones 25 (2009), pp. 245-258. 


\section{Diputación Provincial de Granada \\ Ayuntamiento de Villablino \\ Ayuntamiento de Benavente \\ Ayuntamiento de Tudela de Duero \\ Ayuntamiento de Aguilar de Campoo \\ Ayuntamiento de Gavà \\ Ayuntamiento de Sabadell \\ Mancomunidad Sierra Suroeste \\ Diputación Provincial de Cáceres \\ Ayuntamiento de Villanueva del Pardillo}

Asistencia (o impartición) a cursos, seminarios, congresos y jornadas con contenido que tenga relación directa con las funciones de la plaza a la que se opta.

Formación reglada, no reglada y ocupacional relacionada con el puesto.

Ayuntamiento de San Martín del Rey Aurelio

Consejo Insular de Mallorca

Ayuntamiento de Benavente

Ayuntamiento de Aguilar de Campoo

Ayuntamiento de Gavà

Ayuntamiento de Sabadell

Mancomunidad Sierra Suroeste

Diputación provincial de Cáceres

Ayuntamiento de Villanueva del Pardillo

Antigüedad como desempleado/a en la Oficina del Servicio Público de Empleo de la que dependa el Ayuntamiento.

Ayuntamiento de San Martín del Rey Aurelio

\section{Cargas familiares.}

Ayuntamiento de San Martín del Rey Aurelio

\section{Situación económica de la unidad familiar.}

Ayuntamiento de San Martín del Rey Aurelio

\section{Conocimientos de la lengua catalana.}

Consejo Insular de Mallorca

Ayuntamiento de Gavà

\section{Conocimientos de euskera.}

Ayuntamiento de Barakaldo

Cursos de informática a nivel usuario.

Consejo Insular de Mallorca 
La experiencia profesional en puestos iguales o similares a la plaza convocada $^{38}$ y la formación, tanto académica como complementaria, son los criterios de valoración comunes a la mayoría de las administraciones públicas contratantes.

En algunos casos se plantea un requisito de admisión al proceso, también como un mérito valorable, lo cual no tiene ningún sentido ${ }^{39}$.

\subsection{Buenas prácticas ${ }^{40}$}

El análisis y descripción del puesto debería representar el punto de partida para las entidades que quieren contratar a una o un Agente de Igualdad, ya que el conocimiento de lo que sucede en el puesto de trabajo es la mejor base para la calificación y valoración de los puestos de trabajo y de las personas.

Por tanto, en este apartado (en base a lo analizado en las convocatorias de carácter público de 2010) nos parece interesante terminar señalando de una manera gráfica, el marco idóneo en materia de contratación de Agentes de Igualdad. El objetivo no es otro, que el de aportar un granito de arena a la dignificación de la figura profesional.

\section{Condiciones generales}

\section{Funcionario/a de carrera o}

personal laboral

\section{Carácter fijo}

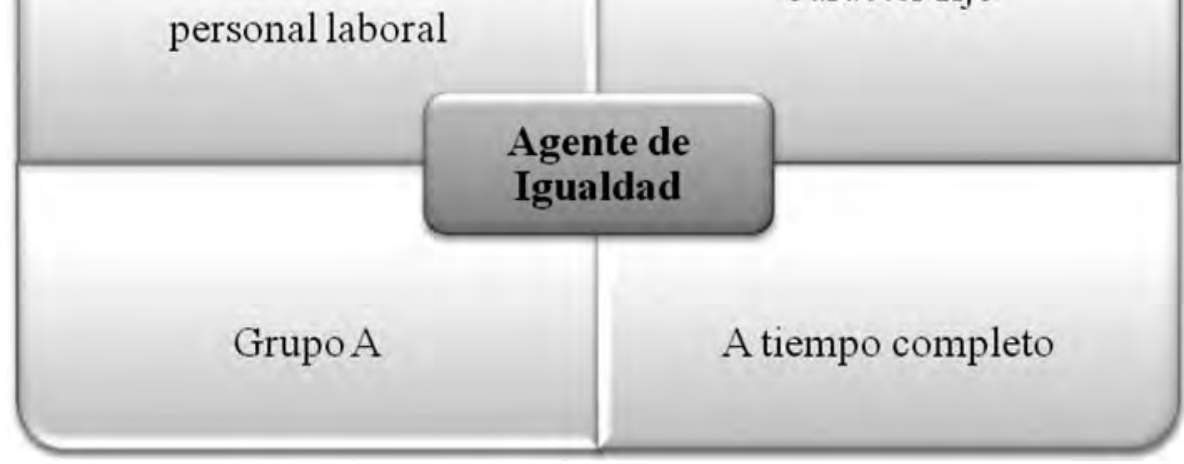

38. Algunas administraciones diferencian (otorgándole distinto peso en el baremo de puntuación) la experiencia adquirida en una administración pública, de la experiencia obtenida en el sector privado.

39. Los Ayuntamientos de Villablino y de Aguilar de Campoo plantean como requisito y mérito valorable al mismo tiempo, la posesión de una Titulación de Grado Medio o Superior en el ámbito de las Ciencias Sociales o Jurídicas.

40. Una buena práctica tiene que cumplir, al menos, con las siguientes características: que sea transferible, pertinente y con un impacto demostrable. 
Requisitos (mínimos) 41

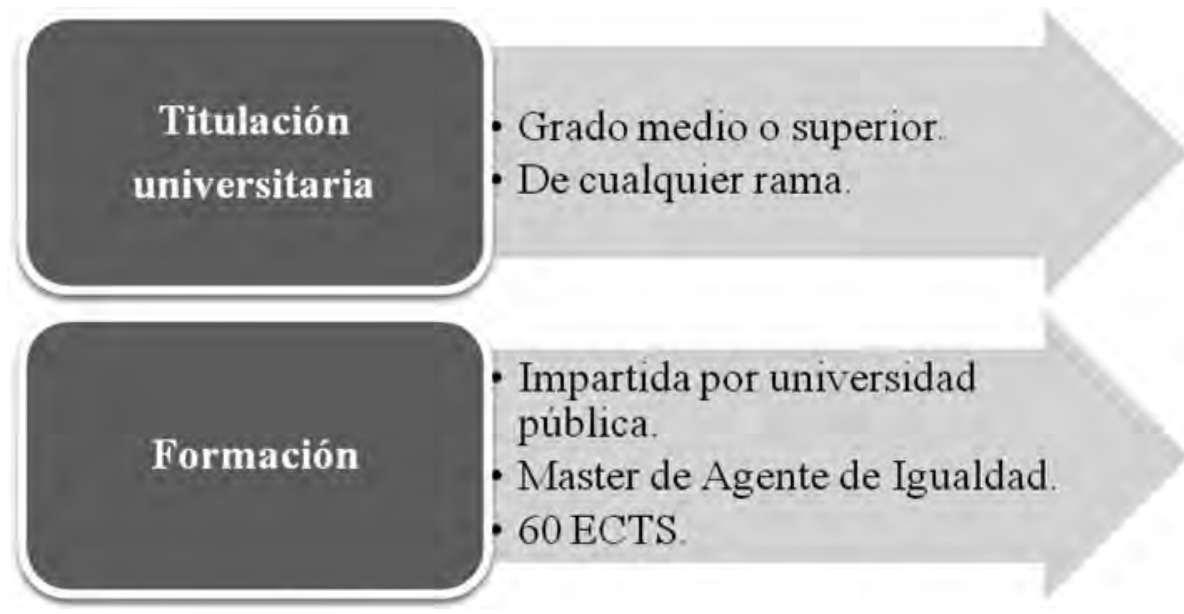

Criterios de valoración

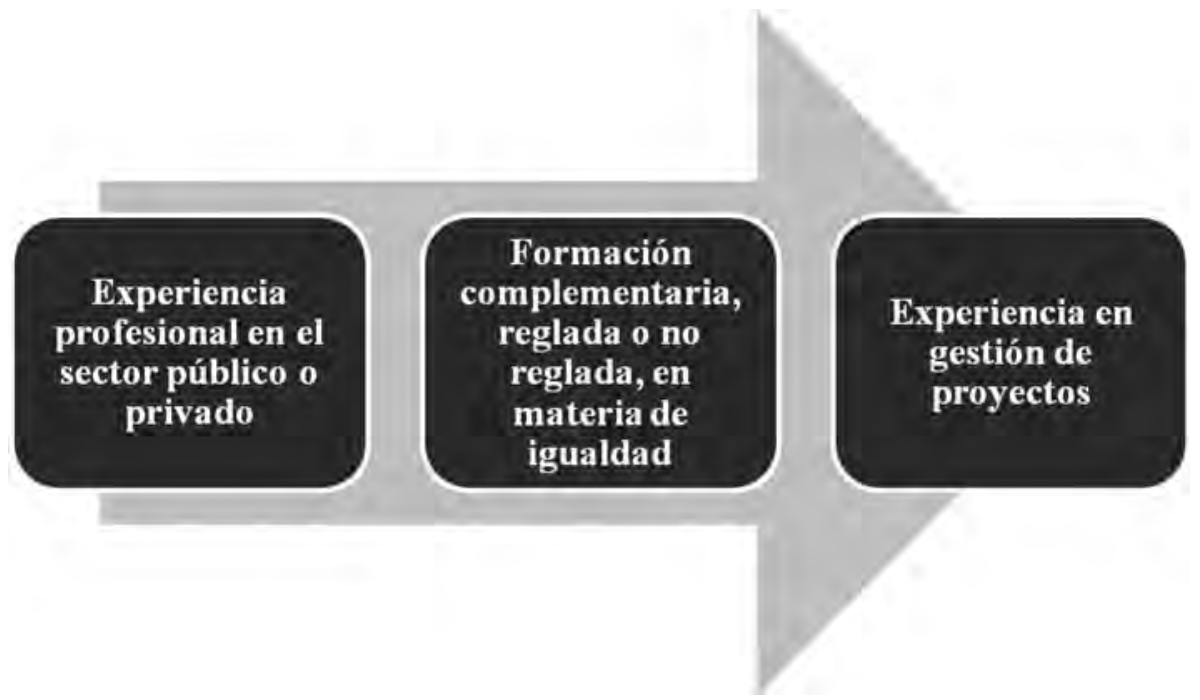

41. Al mismo tiempo, habrá que establecer un camino de homologación de la acreditación de la formación y experiencia ya adquiridas, a la espera de una certificación profesional que marque un punto de inicio en el reconocimiento de competencias (sea cual sea su vía de adquisición).

Por otro lado, es interesante señalar la importancia de algunas competencias básicas a la hora de desempeñar adecuadamente el trabajo de Agente de Igualdad como: la iniciativa, la autonomía, el trabajo en equipo y la comunicación. 
Funciones (básicas) como AlO

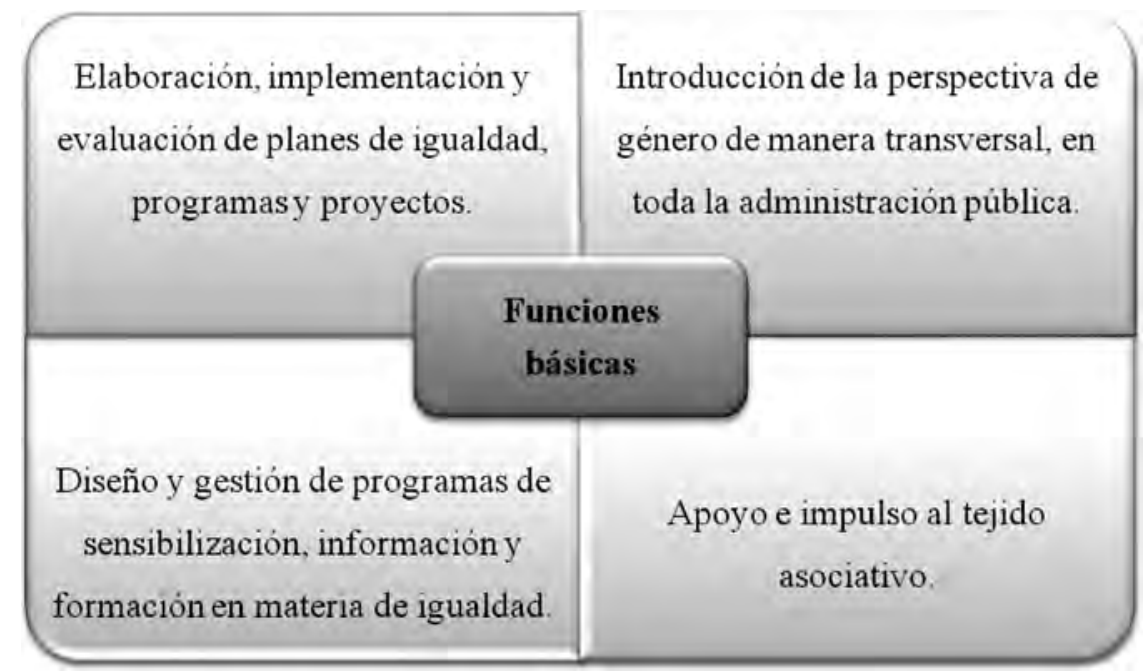

Sistema oposición: temario (bloques básicos) ${ }^{42}$
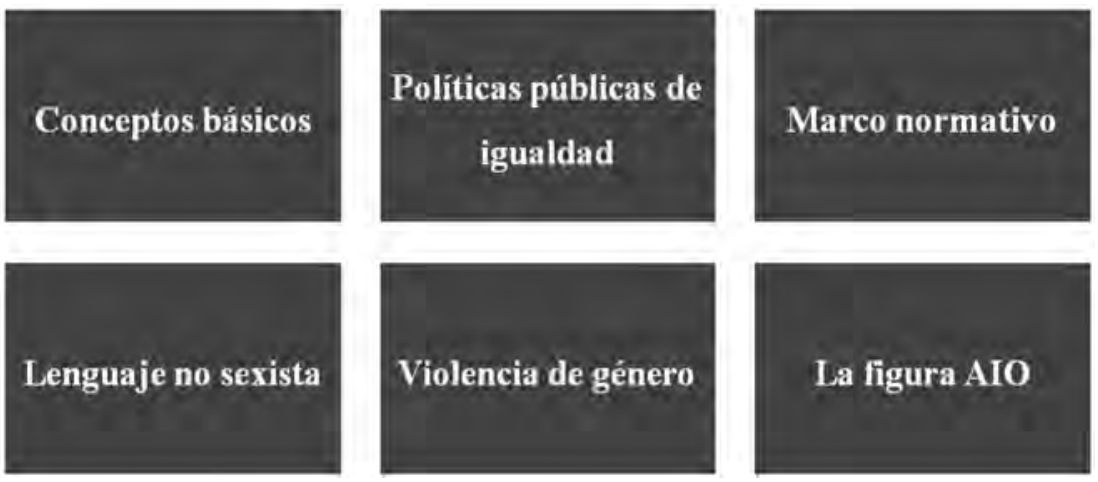

\section{Agente de Igualdad: una figura poco reconocida en Francia}

En Francia, el principio de igualdad de derechos entre hombres y mujeres viene recogido en el preámbulo de la Constitución de 1946 y ha sido objeto de numerosas disposiciones reglamentarias y legislativas.

Los primeros pasos en la creación de puestos de trabajo relacionados con la promoción de la igualdad en la administración pública se remontan al año

42. En el bloque "Políticas públicas de igualdad" incluimos los siguientes instrumentos (esenciales) para su estudio teórico y práctico: planes de igualdad, informes de impacto de género y presupuestos públicos con enfoque de género. 
1974. Aunque no existiera una administración central en este terreno, la entonces Secretaria de Estado de la Condición femenina, Françoise Giroud, puso la primera piedra de una administración descentralizada mediante el nombramiento de las primeras Delegadas Regionales de la Condición Femenina (voluntarias), bajo la autoridad de las y los Prefecto/as ${ }^{43}$. Diez años más tarde, se creó el Servicio de los Derechos de las Mujeres ${ }^{44}$, administración central dotada de personal dependiente del Ministerio de los Derechos de la Mujer establecido por François Mitterrand, así como los puestos de Delegadas Regionales y de Agentes Departamentales de los Derechos de la Mujer.

Hoy en día, si bien existen carreras especializadas y puestos de trabajo específicos en este campo, no consta en la clasificación nacional de las certificaciones profesionales ningún título, certificado profesional o certificado de cualificación en materia de igualdad ${ }^{45}$. Sin embargo, la clasificación operacional de las profesiones del sector privado ${ }^{46}$ registra (sólo) una figura específica: "Agente de información sobre los derechos de las mujeres" (código K1205), cuando en la clasificación interministerial de las profesiones del Estado no consta ninguna ${ }^{47}$.

\section{Oferta formativa específica}

Todavía hay poca oferta formativa que ofrezca una preparación específica para los puestos de Agente de Igualdad en Francia. Esta situación refleja la difícil institucionalización de los estudios feministas y sobre género, debido a distintos motivos como la postura de las feministas, las características propias del sistema universitario o el papel desempeñado por las instancias políticas, y en particular por el feminismo de $\mathrm{Estado}^{48}$. Sin embargo, se nota una evolución desde la mitad de la década del 2000, con la creación de nuevos diseños formativos. En otoño de 2011, contaremos con dos Masters profesionales, dos títulos (inter)universitarios y tres Masters enfocados a la investigación ${ }^{49}$. Se añaden también a estas formaciones de larga duración, y con obtención

43. Revillard, A., La cause des femmes dans l'État: Une comparaison France-Québec (1965-2007). Paris, 2008.

44. Su denominación ha pasado a ser Servicio de los Derechos de las Mujeres y de la Igualdad (Service des Droits des Femmes et de l'Égalité o SDFE) en el año 2000, y en la actualidad depende del Ministerio de las Solidaridades y de la Cohesión Social: www.solidarite.gouv.fr.

45. www.cncp.gouv.fr.

46. http://www2.pole-emploi.fr/espacecandidat/romeligne/Rlilndex.do.

47. http://rime.fonction-publique.gouv.fr

48. Le Feuvre, N., Andriocci, M., "The Impact of Women's Studies on Women's Employment Opportunities and Experiences in France", Griffin. Employment, Equal Opportunities and Women's Studies: Women's Experiences in Seven European Countries. Berlin 2005, pp. 16-50.

49. Masters "Género(s), Reflexiones sobre la diferencia, Relaciones inter-géneros" (Universidad de Paris 8, 1974), "Género, política y sexualidad" (Escuela de los Altos Estudios en Ciencias Sociales, 2005) y "Género y desarrollo" (Universidad de Paris 7, 2010). Aún sin ofrecer una preparación específica, forman a estudiantes que pueden presentarse a los procedimientos de contratación de Agentes de Igualdad. 
de título, formaciones de duración corta como el ciclo "Género, formación, orientación, trabajo", ofrecido dos veces al año por el Conservatorio Nacional de Artes y Oficios de París (2000), u otras formaciones cortas que se impartirán, en un futuro próximo, dentro del programa de investigación y enseñanza de conocimientos sobre género del Instituto de Estudios Políticos de París, iniciado en 2010.

Formaciones académicas que preparan para los puestos de Agente de Igual$\operatorname{dad}^{50}$

\begin{tabular}{|l|c|c|c|}
\hline \multicolumn{1}{|c|}{ Denominación } & Título & Centro & Creación \\
\hline Género y Políticas Sociales & Máster Profesional & $\begin{array}{c}\text { Universidad Toulouse } \\
\text { I - Le Mirail }\end{array}$ & 1993 \\
\hline $\begin{array}{l}\text { Asesor-a Mediador-a Género y } \\
\text { Sexualidades }\end{array}$ & DESS ${ }^{51}$ & Universidad de Reims & $\begin{array}{c}2000 \text { (cerrado } \\
\text { en 2006) }\end{array}$ \\
\hline $\begin{array}{l}\text { Igualdad de oportunidades entre } \\
\text { mujeres y hombres }\end{array}$ & $\begin{array}{c}\text { Título inter- } \\
\text { universitario }\end{array}$ & $\begin{array}{c}\text { Universidades Paris 3 } \\
\text { y Paris 6 }\end{array}$ & 2005 \\
\hline $\begin{array}{l}\text { Consultor-a Igualdad Mujeres / } \\
\text { Hombres }\end{array}$ & Título universitario & $\begin{array}{c}\text { Universidad de } \\
\text { Montpellier }\end{array}$ & 2010 \\
\hline $\begin{array}{l}\text { Estudios sobre Género relacionados } \\
\text { con la Igualdad en la Sociedad }\end{array}$ & $\begin{array}{c}\text { Máster Europeo } \\
\text { Profesional }\end{array}$ & $\begin{array}{c}\text { Universidad de } \\
\text { Lyon 2 }\end{array}$ & 2011 \\
\hline
\end{tabular}

\section{Los puestos de trabajo en la administración pública francesa}

En Francia, los puestos de trabajo dedicados a la promoción de la igualdad en la administración pública ${ }^{52}$ aún son relativamente pocos. El Servicio de los Derechos de las Mujeres y de la Igualdad (SDFE), creado en 1984, emplea en la actualidad una veintena de personas denominadas "responsables", "auxiliares"

50. Se indican aquí las denominaciones y los títulos en su versión actual.

51. NdT: DESS = Título de tercer ciclo de Estudios Superiores Especializados.

52. En Francia, existen tres divisiones en la administración pública: función pública del Estado, función pública territorial y función pública hospitalaria. Este artículo no hace caso de la función pública hospitalaria, ya que hasta la fecha ha invertido poco en cuestiones de igualdad. La función pública del Estado (un 50\% de la plantilla) ejerce en las administraciones centrales (Ministerios), los servicios descentralizados (Prefecturas, Rectorados, Direcciones regionales y departamentales, etc.) y centros públicos que tienen un carácter administrativo. La función pública territorial (un 30\% de la plantilla) ejerce en las colectividades territoriales (Regiones, Departamentos, Municipios) y sus agrupamientos así como en sus centros públicos (Centros comunales de acción social, Oficinas públicas del hábitat, etc.). Con lo cual, en francés, se usa la palabra "déconcentration" cuando se trata de la descentralización de la administración pública del Estado (sistema de delegación hacia niveles internos inferiores), y la palabra "décentralisation" cuando se refiere al proceso de transferencia de competencias del Estado hacia las colectividades territoriales. 
o "agentes". En su red, 28 puestos de Delegadas regionales (Déléguées Régionales aux Droits des Femmes et à l'Égalité o DRDFE), 15 puestos de auxiliares DRDFE y 87 puestos de agentes departamentales (Chargé-e-s de Mission Départementale aux Droits des Femmes et à l'Égalité o CMDDFE) están asignados o pendientes de asignación. Los equipos a veces cuentan con personal de apoyo para sus proyectos, el cual viene denominado como "colaborador/a" (46), "asistente" (3) o "secretario/a" (17), y que, en algunos casos, parecen ejercer, por lo menos en parte, actividades de Agente de Igualdad.

Por otro lado, el Observatorio de la paridad entre mujeres y hombres $(\mathrm{Ob}$ servatoire de la Parité entre les Femmes et les Hommes o OPFH), fundado en 1995 y que depende directamente del gabinete del Primer Ministro, es otra estructura específica que desempeña un papel en la promoción de la igualdad. Cuenta hasta la fecha con una Secretaria General y una Secretaria General suplente.

La llegada de la "izquierda plural" a la cabeza del gobierno (1997-2002) ha sido un período favorable para la integración de las cuestiones de igualdad en la administración pública, con la implantación de varias medidas que aspiraban a crear una cultura interna ${ }^{53}$, por ejemplo: la inclusión de la variable sexo en los datos estadísticos de las administraciones públicas (2000), la creación de un Comité director para la igualdad de acceso a los empleos superiores de las administraciones públicas (2000), la redacción de convenios interministeriales para la promoción de la igualdad de oportunidades en el sistema educativo (2000 y 2006) o el impulso en los distintos ministerios para que éstos se dotaran de planes de acción plurianuales, con el fin de incorporar a la mujer en sus diferentes servicios (2000 y 2004). En 2004, la redacción de una Carta de la igualdad ${ }^{54}$ explicita el nuevo enfoque desarrollado por el SDFE, basado en el gender mainstreaming ${ }^{55}$, e invita a los servicios del Estado y a los entes territoriales a presentar sus acciones a favor de la igualdad.

En varios ministerios, se han desarrollado proyectos específicos, movilizando equipos de entre una a cuatro persona(s) denominada(s) "director/a", "responsable", "jefe/a de proyecto", "agente", "agregada científica", "encargado/a de estudios" ${ }^{\prime \prime 6}$. En la administración central del Ministerio de Educación nacional, Juventud y Vida asociativa, existe un "Proyecto de prevención de las discriminaciones e igualdad entre niñas y niños" que ha supuesto, que desde

53. Dauphin, S., "Apports et limites de l'approche intégrée de l'égalité en France". Santé, société et solidarité 1 (2008), pp. 165-170.

54. Realizada bajo el impulso de la entonces Ministra encargada de la Igualdad, Nicole Ameline, con la colaboración del SDFE y de su red. Este documento, entregado oficialmente al Primer Ministro el 8 de marzo, aspiraba a concretar el "fuerte compromiso del Estado francés" en materia de igualdad, y a congregar a numerosos actores en "una verdadera dinámica de cambio". Para más información: www.solidarite.gouv.fr.

55. Estrategia europea para la integración de la perspectiva de género desarrollada desde 1995 en los países de la Unión. Para más información: http://ec.europa.eu/social.

56. Excluido el personal administrativo, financiero y dedicado a la comunicación. 
el año $2000^{57}$, se hayan creado puestos (estamos hablando de 30 puestos en la actualidad) en las distintas administraciones desconcentradas (Rectorats). Por otro lado, desde 2001 existen dos iniciativas en el seno del Ministerio de Enseñanza Superior e Investigación: un "Proyecto para la paridad en la investigación y la enseñanza superior" -renombrado, en 2008, "Proyecto para la paridad y la lucha contra las discriminaciones" - y un "Proyecto para el lugar de las mujeres en el CNRS 58 ".

Entre 2001 y 2006, los proyectos de promoción de la igualdad, cofinanciados por el Fondo Social Europeo, han supuesto la creación de puestos en 11 universidades, 2 Escuelas de Ingeniería y 3 Institutos de Formación de Maestro/as. Si bien la mayoría de ellos fueron suprimidos cuando se interrumpió la financiación europea, en la actualidad se mantienen unos quince puestos $^{59}$. También se pueden destacar las siguientes iniciativas: el "Proyecto nacional Igualdad de oportunidades entre mujeres y hombres" en la enseñanza superior agrícola y el "Proyecto de la paridad y la igualdad profesionales" del Ministerio de Ecología, Desarrollo sostenible, Transporte y Vivienda.

En el seno de la administración pública territorial, son principalmente los Consejos regionales y los Ayuntamientos, los que han creado puestos de trabajo específicos. El lanzamiento de la Carta europea para la igualdad de las mujeres y los hombres en la vida local ${ }^{60}$ (2006) y las adaptaciones locales de la Agenda 2161, han sido hechos positivos para que el ámbito de la igualdad fuera tomado en cuenta. Por otro lado, las entidades locales, así como los demás servicios del Estado, también pueden solicitar la "etiqueta de igualdad"62 (2004) que han conseguido, a día de hoy, el Ayuntamiento de Rennes y el Consejo regional de Picardía.

No existe ninguna lista pública que haga una síntesis de la totalidad de los puestos existentes. Sin embargo, según fuentes internas, 9 de las 26 regiones habrían nombrado "agentes" en varios proyectos: "Igualdad de mujeres y hombres", "Igualdad mujeres/hombres y lucha contra las discriminaciones", "Lucha contra las discriminaciones", "Igualdad de los derechos e innovación social", "Europa" y "Orientación de la formación profesional".

Un estudio realizado por la Alta Autoridad de Lucha contra las Discriminaciones y para la Igualdad (Haute Autorité de Lutte contre les Discriminations

57. Tras un primer intento sin éxito en 1984.

58. NdT: CNRS = Centro nacional de la investigación científica.

59. En la actualidad se está trabajando en un censo de los puestos de trabajo, así como en un proyecto de conferencia nacional de las y los Agentes de Igualdad en las universidades.

60. www.ccre.org/docs/charte_egalite_es.doc.

61. Plan de acción para el siglo XX adoptado por 173 jefes de Estado en 1992, y que, entre otras cuestiones, fomenta las "acciones a favor de la participación de las mujeres en el desarrollo sostenible y equitativo".

62. Dirigida en un primer momento a las empresas privadas y entregada por el organismo certificador AFNOR. 
et pour l'Égalité o HALDE) ${ }^{63}$ en grandes ciudades y aglomeraciones ${ }^{64}$ indica que 23 de las 32 entidades participantes han firmado cartas mediante las cuales se comprometían en materia de prevención de las discriminaciones y de promoción de la igualdad, 19 han confiado delegaciones específicas a cargos electos, 12 han movilizado financiación sobre estas temáticas, y 9 han puesto en marcha acciones específicas en materia de igualdad (apoyo a asociaciones o acciones propias). Tampoco existe una lista pública que resuma los puestos creados en los distintos municipios. Los proyectos específicos identificados, cuentan con un equipo de entre una a ocho persona(s), cuyo puesto se denomina de varias formas: "responsables", "agentes", "encargado/as de proyecto" o "jefe/as de proyecto".

Algunos proyectos de los entes territoriales que emplean Agentes de Igualdad ${ }^{65}$

\begin{tabular}{|l|l|}
\hline 2001 & $\begin{array}{l}\text { Proyecto de Igualdad - Derechos de las mujeres del Ayuntamiento } \\
\text { de Rennes. }\end{array}$ \\
\hline 2002 & $\begin{array}{l}\text { Observatorio de la igualdad entre mujeres y hombres del Ayunta- } \\
\text { miento de París. }\end{array}$ \\
\hline 2005 & $\begin{array}{l}\text { Casa de la igualdad mujeres-hombres del Ayuntamiento de Échiro- } \\
\text { lles. }\end{array}$ \\
\hline 2008 & $\begin{array}{l}\text { Proyecto de lucha contra las discriminaciones y para la igualdad en- } \\
\text { tre mujeres y hombres del Ayuntamiento de Reims. }\end{array}$ \\
\hline 2009 & Proyecto de lgualdad del Ayuntamiento de Toulouse. \\
\hline
\end{tabular}

\subsection{Las modalidades de contratación}

La falta de certificación y el poco reconocimiento de la profesión, conllevan una escasa regulación en la contratación de las y los Agentes de Igualdad.

La administración pública francesa emplea actualmente a unos cinco millones de personas. La mayoría de ellas tienen el estatus de funcionario/a, es decir, que han sido confirmados en sus puestos después de aprobar oposiciones tanto externas como internas (oposiciones específicas a cada una de las tres funciones públicas). Todas estas pruebas se segmentan en tres categorías (A, B y C) dependiendo del nivel de estudios (título obtenido o equivalente) y del nivel del puesto. En la mayoría de ellas, no se exige haber seguido un plan

63. Esta autoridad administrativa independiente creada en 2004, tiene poderes de investigación, mediación, recomendación y sanción. Entre otras cuestiones, publica varios estudios e informes al año (www.halde.fr).

64. HALDE, Prévention des discriminations et promotion de l'égalité: que répondent les grandes villes et agglomérations à la HALDE? Paris, 2007, p. 6.

65. En los proyectos mencionados, se indica aquí su designación actual. 
de estudio específico. La remuneración del funcionariado se define en base a un cuadro estándar que tiene en cuenta el centro de destino, la categoría, el puesto y la antigüedad. No existe a día de hoy ninguna oposición específica para contratar a personal dedicado a las cuestiones de igualdad.

Algunas características de las oposiciones de la administración pública en Francia

\begin{tabular}{|l|c|c|c|}
\hline \multicolumn{1}{|c|}{ Categoría } & A & B & C \\
\hline Requisitos mínimos & $\begin{array}{c}\text { Bachillerato+3 } \\
\text { años }\end{array}$ & Bachillerato & / \\
\hline Tipo de puesto & De dirección & De ejecución & De obra \\
\hline Puestos / año & 20000 & 4000 & 3000 \\
\hline Sueldo mín. / máx.* $^{*}$ & $1732 / 2101 €$ & $1323 / 1418 €$ & $1336 / 1341 €$ \\
\hline
\end{tabular}

* Sueldo bruto mensual (sin indemnizaciones), al inicio de la carrera.

Fuente: www.fonction-publique.gouv.fr

La administración también procede a emplear personal por contrato temporal de derecho público "cuando busca perfiles o competencias específicas" 66 . Las ofertas se publican en la Bolsa interministerial de empleo público ${ }^{67}$, que aunque se destina principalmente a los agentes públicos que desean efectuar un traslado, también propone empleos contractuales. Los procesos de selección de estas contrataciones externas sin oposición, se asimilan a los del sector privado: envío de documentación con CV y carta de presentación, que examina una comisión constituida por un mínimo de tres personas, y realización de entrevistas, después de las cuales "la comisión establece, por orden de mérito, la lista de candidaturas aptas para la contratación" ${ }^{68}$. A los seis años, el contrato temporal tiene que ser convertido en contrato fijo si la administración quiere seguir trabajando con estos/as profesionales.

El SDFE es la administración donde la contratación de los Agentes de Igualdad parece en la actualidad más consolidada. En los años ochenta, bajo la dirección de la Ministra Yvette Roudy, la contratación se ha realizado en gran medida entre (grupos de) militantes feministas. En los años noventa, se adoptó una "estrategia de contratación de personal con un perfil administrativo más "clásico»" defendida como "estrategia que apuntaba a una mejor eficacia política" ${ }^{\prime 69}$. Se valoraban entonces las competencias técnicas y el conocimiento

66. http://concours.fonction-publique.gouv.fr.

67. www.biep.gouv.fr.

68. http://concours.fonction-publique.gouv.fr.

69. Revillard, A., La cause des femmes dans l'État, p. 203. 
del engranaje de la administración. A raíz de la Reforma general de las políticas públicas, varias circulares del Primer Ministro del $2008^{70}$ han vuelto a definir las relaciones y los proyectos de las y los DRDFE y CMDDFE y, en 2009, un decreto especificaba los criterios de contratación con respecto "al delegado regional de los derechos de las mujeres y la igualdad" (sic). Teóricamente puede ser nombrado DRDFE el funcionariado de categoría A o asimilado, los o las magistrado/as, los o las oficiales así como agentes contractuales de nivel equivalente ${ }^{71}$, con la condición de que tengan "competencias o experiencia en ámbitos útiles para la promoción de los derechos de las mujeres y de igualdad entre mujeres y hombres" ${ }^{\prime \prime 2}$. Se indica que una persona no puede ocupar un mismo puesto más de seis años. Al final, muchas/os Agentes de Igualdad tienen contrato temporal, y eso se traduce en una situación laboral relativamente precaria ya que no se pueden beneficiar de las ventajas del funcionariado de la administración pública (sueldo, seguro de salud, promoción, etc.).

A día de hoy, los servicios desconcentrados de la Educación nacional ${ }^{73}$ y las Universidades eligen a personas, Agentes de Igualdad, que forman parte de su plantilla como funcionarios/as de carrera, mientras que a principios de 2000, los puestos de trabajo se cubrían con personal laboral. En otras administraciones públicas, la contratación de las y los Agentes de Igualdad parece menos estandarizada, y los procesos de selección están abiertos tanto al funcionariado como al personal laboral.

\subsection{Ofertas de trabajo en el 2010}

Las ofertas de trabajo analizadas a continuación se han compilado a través de la lista de difusión EFiGiES ${ }^{74}$. Si bien probablemente este listado no cubre todas las ofertas publicadas en el 2010, ilustra en una medida correcta las ofertas existentes en el sector.

70. Circulares de 19 de marzo ( $\left.{ }^{\circ} 5285\right), 7$ de julio ( $\left.n^{\circ} 5316\right)$ y 19 de septiembre ( $\left.n^{\circ} 5333\right)$.

71. Nominación formulada por el Ministerio encargado de los derechos de las mujeres y de la igualdad.

72. Decreto 2009-587 con fecha 25 mayo de 2009 sobre las atribuciones de los/as secretario/as generales para los asuntos regionales.

73. El porcentaje de tiempo de trabajo que dedican las y los Agentes de Igualdad a los proyectos de su competencia profesional, varía del 25 al 100\%.

74. Asociación de jóvenes investigadoras e investigadores en estudios feministas, género y sexualidades. Su lista de difusión contribuye a dar a conocer informaciones académicas y profesionales relacionadas con este campo. Para más información: www.efigies.org. 


\section{Condiciones}

\begin{tabular}{|c|c|c|}
\hline Puesto & Organismo contratante & $\begin{array}{l}\text { Categoría / Régimen / } \\
\text { Requisitos de titulación }\end{array}$ \\
\hline Agente de Igualdad & $\begin{array}{l}\text { Dirección General de la Cohesión } \\
\text { Social / SDFE. }\end{array}$ & $\begin{array}{l}\text { Agregado/a de la } \\
\text { administración central o } \\
\text { Agente de categoría A. }\end{array}$ \\
\hline $\begin{array}{l}\text { Auxiliar del jefe de } \\
\text { oficina }\end{array}$ & $\begin{array}{l}\text { Dirección General de la Cohesión } \\
\text { Social / SDFE / Oficina de animación y } \\
\text { observación. }\end{array}$ & No consta. \\
\hline Agente de Igualdad & $\begin{array}{l}\text { Dirección General de la Cohesión } \\
\text { Social / SDFE / Oficina de animación y } \\
\text { observación. }\end{array}$ & No consta. \\
\hline $\begin{array}{l}\text { Auxiliar DRDFE Midi- } \\
\text { Pirineos }\end{array}$ & $\begin{array}{l}\text { Secretaría General de Asuntos } \\
\text { Regionales de Midi-Pirineos / Servicio } \\
\text { Central de la Dirección General de la } \\
\text { Cohesión Social. }\end{array}$ & $\begin{array}{l}\text { Funcionario/a }{ }^{75} \text {, nivel } \\
\text { categoría A o puesto de } \\
\text { agente contractual. } \\
\text { Bachillerato+3 años } \\
\text { mínimo, experiencia } \\
\text { profesional deseada. }\end{array}$ \\
\hline CMDDFE Morbihan & $\begin{array}{l}\text { Dirección Departamental de Cohesión } \\
\text { Social y de Protección de la Población } \\
\text { del departamento Morbihan / } \\
\text { Delegación Regional de Derechos de } \\
\text { las Mujeres e Igualdad. }\end{array}$ & \multirow{3}{*}{$\begin{array}{l}\text { Funcionario/a }{ }^{76} \text {, nivel } \\
\text { categoría A o puesto de } \\
\text { agente contractual. } \\
\text { Bachillerato+3 años } \\
\text { mínimo, experiencia } \\
\text { profesional deseada. }\end{array}$} \\
\hline CMDDFE Vosges & $\begin{array}{l}\text { Dirección Departamental de Cohesión } \\
\text { Social y Protección de la Población del } \\
\text { departamento Vosges. }\end{array}$ & \\
\hline CMDDFE Isla-de-Francia & $\begin{array}{l}\text { Dirección Departamental de Cohesión } \\
\text { Social de París. }\end{array}$ & \\
\hline $\begin{array}{l}\text { Responsable del } \\
\text { Proyecto "Paridad } \\
\text { y lucha contra las } \\
\text { discriminaciones" }\end{array}$ & $\begin{array}{l}\text { Dirección General de Investigación } \\
\text { e Innovación / Dirección de la } \\
\text { Enseñanza Superior y la Inserción } \\
\text { Profesional / Servicio de coordinación } \\
\text { estratégica y de territorios. }\end{array}$ & $\begin{array}{l}\text { Funcionario/a o puesto } \\
\text { de agente contractual. } \\
\text { Nivel categoría A. }\end{array}$ \\
\hline
\end{tabular}

75. Ministerio de Empleo, Sanidad y Cohesión Social o mediante destino o nombramiento provisional para refuerzo de otros servicios ministeriales. 


\begin{tabular}{|l|l|l|}
\hline \multicolumn{1}{|c|}{ Puesto } & \multicolumn{1}{|c|}{ Organismo contratante } & \multicolumn{1}{c|}{$\begin{array}{c}\text { Categoría / Régimen / } \\
\text { Requisitos de titulación }\end{array}$} \\
\hline $\begin{array}{l}\text { Responsable de la Casa } \\
\text { de Igualdad mujeres- } \\
\text { hombres }\end{array}$ & Ayuntamiento de Échirolles. & $\begin{array}{l}\text { Puesto contractual. } \\
\text { Nivel categoría A } \\
\text { (agregado/a territorial). }\end{array}$ \\
\hline $\begin{array}{l}\text { Agente de Igualdad del } \\
\text { Proyecto "Lucha contra } \\
\text { las discriminaciones y } \\
\text { derechos de las mujeres" }\end{array}$ & Ayuntamiento de Aubervilliers. & $\begin{array}{l}\text { Puesto contractual. } \\
\text { Nivel categoría A } \\
\text { (agregado/a territorial). }\end{array}$ \\
\hline $\begin{array}{l}\text { Responsable de } \\
\text { proyectos en la Casa } \\
\text { de Igualdad mujeres- } \\
\text { hombres }\end{array}$ & Ayuntamiento de Échirolles. & $\begin{array}{l}\text { Puesto contractual. } \\
\text { Nivel categoría A. }\end{array}$ \\
\hline
\end{tabular}

Para todos los puestos, la contratación corresponde al nivel de la categoría A. Se supone que todos los puestos ofertados lo son a jornada completa. No consta información sobre la retribución de dichos puestos.

\section{Requisitos}

\begin{tabular}{|l|l|l|}
\hline \multicolumn{1}{|c|}{ Puesto } & \multicolumn{1}{|c|}{ Competencias } & \multicolumn{1}{c|}{ Formación como AIO } \\
\hline $\begin{array}{l}\text { Agente de Igualdad } \\
\text { (SDFE). }\end{array}$ & $\begin{array}{l}\text { Negociación y dirección de reuniones, con- } \\
\text { cepción e innovación, capacidad de redac- } \\
\text { tar y sintetizar / rigor. }\end{array}$ & $\begin{array}{l}\text { Interés por las cuestiones re- } \\
\text { lativas a los derechos de las } \\
\text { mujeres y a la igualdad entre } \\
\text { mujeres y hombres. }\end{array}$ \\
\hline $\begin{array}{l}\text { Auxiliar del jefe de } \\
\text { oficina (SDFE). }\end{array}$ & $\begin{array}{l}\text { Buen conocimiento de la organización del } \\
\text { Estado / capacidad de redacción, iniciativa, } \\
\text { rigor, capacidad de negociación, capacidad } \\
\text { de síntesis y análisis, experiencia confirma- } \\
\text { da en la dirección de un equipo / discreción. }\end{array}$ & $\begin{array}{l}\text { Interés por las cuestiones re- } \\
\text { lativas a los derechos de las } \\
\text { mujeres y a la igualdad entre } \\
\text { mujeres y hombres. }\end{array}$ \\
\hline $\begin{array}{l}\text { Agente de Igualdad } \\
\text { (SDFE). }\end{array}$ & $\begin{array}{l}\text { Buen conocimiento de la organización del } \\
\text { Estado, de la prensa y de internet, buen } \\
\text { manejo de las herramientas informáticas / } \\
\text { interés por la comunicación, capacidad de } \\
\text { síntesis y análisis, capacidad de redacción / } \\
\text { rigor, discreción. }\end{array}$ & No consta. \\
\hline
\end{tabular}




\begin{tabular}{|c|c|c|}
\hline Puesto & Competencias & Formación como AlO \\
\hline $\begin{array}{l}\text { Auxiliar DRDFE Mi- } \\
\text { di-Pirineos. }\end{array}$ & $\begin{array}{l}\text { Conocimiento del funcionamiento de la ad- } \\
\text { ministración, del entorno económico y polí- } \\
\text { tico, de Europa, conocimiento y manejo de } \\
\text { las herramientas informáticas / capacidad de } \\
\text { redacción, capacidad de dirigir una reunión } \\
\text { y fluidez oral, fuerte interés por los trabajos } \\
\text { de cooperación en equipo e interministeria- } \\
\text { les / autonomía e iniciativa, lealtad y fiabili- } \\
\text { dad, seriedad e imparcialidad. }\end{array}$ & $\begin{array}{l}\text { Sensibilidad en materia de } \\
\text { igualdad y conocimiento del } \\
\text { concepto de género. }\end{array}$ \\
\hline CMDDFE Morbihan. & \multirow{3}{*}{$\begin{array}{l}\text { Conocimientos necesarios en los ámbitos } \\
\text { económico, social, administrativo / se valo- } \\
\text { ran conocimientos del entorno de la empre- } \\
\text { sa y del funcionamiento de las asociaciones } \\
\text { / don de gentes y capacidad de negociación, } \\
\text { convicción, capacidad de redacción / auto- } \\
\text { nomía. }\end{array}$} & \multirow{3}{*}{ No consta. } \\
\hline CMDDFE Vosges. & & \\
\hline $\begin{array}{l}\text { CMDDFE Isla-de- } \\
\text { Francia. }\end{array}$ & & \\
\hline $\begin{array}{l}\text { Responsable del } \\
\text { Proyecto "Paridad y } \\
\text { lucha contra las dis- } \\
\text { criminaciones". }\end{array}$ & $\begin{array}{l}\text { Conocimiento de los entornos de la ense- } \\
\text { ñanza superior y la investigación / capaci- } \\
\text { dad de redacción, experiencia de dirección, } \\
\text { don de gentes, capacidad de síntesis / buena } \\
\text { comunicación y presencia, iniciativa y con- } \\
\text { vicción. }\end{array}$ & $\begin{array}{l}\text { Interés por las cuestiones } \\
\text { relativas a la paridad y a la } \\
\text { lucha contra las discrimina- } \\
\text { ciones. }\end{array}$ \\
\hline $\begin{array}{l}\text { Responsable de la } \\
\text { Casa de Igualdad } \\
\text { mujeres-hombres. }\end{array}$ & $\begin{array}{l}\text { Buenos conocimientos de la cooperación } \\
\text { entre municipios / experiencia en el ámbito } \\
\text { de la política urbana, dirección, gestión de } \\
\text { proyectos, gestión del cambio, animación } \\
\text { de redes. }\end{array}$ & $\begin{array}{l}\text { Habilidades en materia de } \\
\text { igualdad y su aplicación en } \\
\text { las políticas locales. }\end{array}$ \\
\hline $\begin{array}{l}\text { Agente de Igualdad } \\
\text { del Proyecto "Lucha } \\
\text { contra las discrimi- } \\
\text { naciones y derechos } \\
\text { de las mujeres". }\end{array}$ & $\begin{array}{l}\text { Experiencia en la animación de redes de } \\
\text { cooperación, dirección, gestión de proyec- } \\
\text { tos, capacidad de redacción. }\end{array}$ & $\begin{array}{l}\text { Conocimientos del marco } \\
\text { normativo e institucional en } \\
\text { materia de lucha contra las } \\
\text { discriminaciones y de pro- } \\
\text { moción de los derechos de } \\
\text { las mujeres. }\end{array}$ \\
\hline $\begin{array}{l}\text { Responsable de pro- } \\
\text { yectos en la Casa de } \\
\text { lgualdad mujeres- } \\
\text { hombres. }\end{array}$ & $\begin{array}{l}\text { Conocimiento del funcionamiento de los } \\
\text { entes locales, buen manejo de las herra- } \\
\text { mientas informáticas / experiencia en la } \\
\text { dirección de proyectos de cooperación, } \\
\text { gestión de proyectos, animación de redes, } \\
\text { dirección, capacidad de redacción / interés } \\
\text { por la pedagogía. }\end{array}$ & $\begin{array}{l}\text { Conocimiento amplio de } \\
\text { cuestiones de género y su } \\
\text { aplicación en las políticas } \\
\text { locales. } \\
\text { Experiencia en el montaje } \\
\text { de proyectos relacionados } \\
\text { con la igualdad mujeres- } \\
\text { hombres. }\end{array}$ \\
\hline
\end{tabular}


Entre los requisitos para la contratación, pocas veces se especifican el nivel (subyacente a la categoría definida) y la materia del título obtenido. Los elementos destacados se refieren a las competencias: conocimientos no regidos de forma obligatoria por títulos (por ejemplo "conocimientos necesarios en los ámbitos: económico, social, administrativo", "buen manejo de las herramientas informáticas"), habilidades (por ejemplo "capacidad de negociación", "capacidad de redacción") y un "saber estar" (por ejemplo "discreción", "imparcialidad"). En ninguna oferta se exige un título específico relacionado con las temáticas de igualdad. A falta de ello, se menciona dependiendo de las ofertas "demostrar habilidades", un "conocimiento amplio de cuestiones de género", un "conocimiento del marco normativo e institucional", una "sensibilidad" especial o un "interés" por las cuestiones de género. El abanico es amplio como podemos ver, ya que se pide desde tener un "simple interés" hasta una competencia o habilidad concreta.

Sorprendentemente con respecto a los puestos de CMDDFE, cuya presentación es estándar y abarca al menos cuatro temáticas (presentación general de la figura de Agente de Igualdad, proyectos, modalidades de acción, perfil del puesto y habilidades requeridas) - a lo cual se añade, en la oferta para la CMDDFE del departamento Vosges, una quinta temática (el contexto local)-, no se alude a competencias requeridas en materia de igualdad. Podemos concluir que éstas parecen desempeñar un papel secundario en los procesos de selección. Además, en abril de 2010, se volvió a cuestionar la transparencia de los criterios de selección cuando fue nominada la nueva DRDFE de la región Países-del-Loire: una persona que no tenía la titulación requerida (Bachillerato+3 años), a costa de una funcionaria del Ministerio de Justicia que había superado el proceso de selección, situándose como primera candidata.

\section{7. ¿Cuál es el futuro de la profesión de Agente de Igualdad en Francia y en España?}

El futuro de los puestos de Agentes de Igualdad en el seno de las administraciones públicas francesa ${ }^{76}$ y española es, a día de hoy, incierto.

76. Allí, la existencia de estructuras dedicadas a la igualdad y creadas desde hace muchos años ha sido recientemente cuestionada. Con la Reforma general de las políticas públicas, las posturas de las DRDFE y CMDDFE han cambiado significativamente, fragilizando su trabajo a nivel local. Antiguamente bajo la autoridad directa de lo/as Prefecto/as, lo/as DRDFE han pasado a depender del Secretariado General de Asuntos Regionales y lo/as CMDDFE a formar parte de las Direcciones Departamentales de Cohesión Social (y de Protección de la Población), donde se agrupan con otros servicios como la acción sanitaria y social, la juventud y los deportes o... ¡los servicios veterinarios! En 2010, el SDFE ha pasado a formar parte de la Dirección General de Cohesión Social, con una reducción de sus recursos tras la pérdida de su centro de documentación y de su página Web. Además, un informe elaborado a instancia del Presidente de la República con vista a "promover la igualdad de oportunidades y la diversidad en nuestro país" recomendaba integrar el OPFH en un "Observatorio de la paridad, la diversidad y la igualdad de oportunidades". 
La actual crisis económica y la pérdida de recursos es hoy una realidad, que dificulta la incorporación y permanencia de las y los especialistas de igualdad en el sector público (no es óbice decir que muchas administraciones optan por recortar en primer lugar los presupuestos destinados a este ámbito de trabajo). No obstante, al mismo tiempo, la igualdad de mujeres y hombres se ha convertido en un valor emergente, en aquellas entidades y empresas, públicas y privadas, que apuestan por un nuevo modelo de trabajo y ven en este principio un camino hacia la competitividad y la productividad perdidas.

Por todo ello, la certificación profesional ${ }^{77}$ de la figura de Agente de Igualdad, la homologación de las condiciones de contratación en el seno de las administraciones públicas (y por qué no también en las organizaciones privadas), así como el refuerzo de las redes de actoras y actores que trabajan en este ámbito, se presentan en la actualidad como ejes fundamentales para asentar la legitimidad de estos puestos y permitir al mismo tiempo a sus titulares, ejercer su profesión en condiciones dignas y justas.

77. "El papel de la certificación es muy significativo. Por un lado permite garantizar la calidad y, por otro, expresar el nivel de competencias profesionales alcanzado. Asimismo para las personas supone una garantía para organizar su propio recorrido formativo y laboral así como facilitarles los procesos de movilidad laboral. La certificación representa, además, un valor añadido para la persona, pues supone un reconocimiento público, otorgándole un status personal dentro y fuera de las instituciones donde desarrolla su trabajo". Ver: Ruiz Bueno, C., La certificación profesional: algunas reflexiones y cuestiones a debate. Barcelona. 